\title{
Optimal Control Strategy of Platform Load Oriented to Network and Load Cooperation
}

\author{
Xuesong Shao (i), Gaoying Cui, Xiao Chen, Xinrong Ji, and Yongxian Yi \\ State Grid Jiangsu Marketing Service Center(Metrology Center), Nanjing, Jiangsu Province 210016, China \\ Correspondence should be addressed to Xuesong Shao; zhao_yuanliang@163.com
}

Received 1 April 2021; Revised 9 May 2021; Accepted 28 May 2021; Published 8 June 2021

Academic Editor: Xiao Ling Wang

Copyright (c) 2021 Xuesong Shao et al. This is an open access article distributed under the Creative Commons Attribution License, which permits unrestricted use, distribution, and reproduction in any medium, provided the original work is properly cited.

\begin{abstract}
In recent years, with the continuous growth of China's power peak load and the rapid development of renewable energy, a large number of renewable energy sources are connected to the power grid, increasing the uncertainty of power grid operation and posing new major challenges to the power system regulation capacity. Flexible load has the characteristics of wide distribution, fast response, and high economy, which is an important control resource for the future power system. Based on the flexible load of commercial buildings and residential users, this paper studies the resource characteristics and response characteristics, clarifies the resource characteristics and demand response characteristic indexes of commercial and residential users, and establishes the response characteristics model of commercial buildings and residential users. Considering the influence of weather, holidays, incentive mechanism, and other factors on the response of flexible load, the quantitative analysis method of flexible load resource regulation potential for regional power grid dispatching was studied, and the feasibility of flexible load resources directly participating in the load control system was analyzed. Based on the uncertainty and mathematical characterization method of the active response of flexible loads, the optimal combination control strategy of demand response resources was proposed to eliminate the problems of heavy load and overload of regional power grid equipment by using the active response ability of flexible loads. Finally, the IEEE 14-node system is selected for simulation verification, which provides a theoretical basis for alleviating the power grid operation pressure in the peak load period of the power grid in the urban core area, improving the safety and economic operation level of regional power grid dispatching and the utilization rate of power grid equipment assets.
\end{abstract}

\section{Introduction}

With the rapid development of China's economy and the increasing load, the contradiction between power supply and demand is further deepened. Flexible load has the advantages of fast response and high economy and reflects different users' willingness to use electricity. Flexible load resources are important interactive resources in the framework of smart grid. Although a single load is not controllable at any time, a large number of small- and medium-sized loads will show a certain overall controllability when gathered together.

In order to make the flexible loads of commercial and residential users better participate in the system scheduling through the demand response project, it is necessary to master the response characteristics when they participate in the demand response project. Domestic and foreign scholars have done a lot of research on this. The literature [1] studies the load regulation technology of a large number of large apartment air conditioning load clusters, studies the regulation characteristics of the air conditioning load cluster, and proposes a regulation method of state cohort based on this characteristic. The literature [2] proposes a new temperature setting adjustment method based on the load regulation characteristics of air conditioning regulated by the state queue method proposed by Lee et al., in order to improve problems such as state absence and load fluctuation in regulation. The literature [3] establishes the first-order 
model of a single air conditioner and establishes the power aggregation model of air conditioning load by using the Latin hypervertical method. After the establishment of the aggregation model, the controllable capacity of air conditioning load is evaluated, and the expression between the controllable capacity and the control temperature and outdoor temperature was obtained. The literature [4] compares three different ways to contract design in which demand response participates in power system regulation for incentive payments. The literature [5] mainly analyzes the relationship between the installation capacity of residents' air conditioning load and residents' characteristic variables. In the literature [6], the status quo of energy consumption of public buildings at home and abroad and the development process of load calculation methods are systematically reviewed and analyzed, the methods of investigation and field measurement of energy consumption of public buildings and the possible problems are discussed, and some suggestions are given. The literature [7] divides the air conditioning load into three industries, which are commercial users, administrative and public institution users, and residential users, and obtains the industry load through the ratio relationship between the industry electric quantity and the number of hours of the maximum load utilization. The literature [8] proposes a demand response scheme using a hopping scheme for consumption scheduling of appliances which can protect the privacy of electricity consumers. The literature [9] proposes a novel demand-side response model, which can be integrated into system scheduling model straightway and enables the optimal scheduling of energy/power consumption of a heterogeneous population of TCLs. The literature [10] analyzes and studies the load control technology of central air conditioning based on demand response. The literature [11] analyzes the response characteristic that the diversity of the load group was destroyed after the air conditioning load group participated in the regulation, proposes the control strategy to maintain the diversity of the air conditioning load group, analyzes the phenomenon of "secondary peak load" after the air conditioning load group was controlled, and puts forward the time-divided load recovery strategy. The literature [12] studies the response characteristics of refrigerated and nonrefrigerated central air conditioning systems used in public buildings. The literature [13] proposes a simple dynamic model on the basis of the analysis, estimation, and control of a variable-output compressor air conditioner (VOCAC).

The literature [14] shows that with the development of smart power grid, the interaction ability of "source-networkload" is improved, and the participation of flexible loads in power grid scheduling makes the management of line overload more flexible and economical. Scholars at home and abroad have studied how to mobilize flexible loads in courts to eliminate heavy load on lines and formed a heavyload elimination mechanism based on electricity price and incentive demand responses. The literature [15] sorts out and analyzes the lessons of the restructuring of the American energy industry based on the natural gas and electric power accidents in California. In the literature [16], a model predictive control (MPC) of distributed air conditioning loads is proposed in order to balance fluctuations in solar power. The literature [17-19] considers the impact of load demand elasticity on power grid power flow from the perspective of users and aims at maximizing users' benefits by establishing reasonable electricity price to guide load transfer from peak period to trough period to eliminate line overload. The literature [20-23] invents interruptible loads to alleviate the problem of overloaded lines. In order to minimize the interruption load, interruption compensation price, and power purchase cost of users, the power flow of heavy-duty lines can be reduced by making reasonable load reduction plan. The literature [24] firstly analyzes different types of power loads, builds user load characteristic quantity that reflects the power consumption characteristics of loads, and then obtains user demand response load curve after the implementation of time-of use electricity price. Then, according to the principle of economics, the demand response behavior of users under the environment of TOU electricity price is analyzed, and the corresponding load reduction and transfer model is constructed. The literature [25] encourages users to respond by sharing the benefits brought by reducing grid congestion with users. However, these results have only been verified in a single-time crosssection and have yet to be verified in a continuous-time cross-section. At the same time, simple electricity price or incentive mechanism is difficult to fully mobilize the active response potential of flexible loads, while the coordinated application of electricity price and incentive mechanism can increase the diversity of choices on the user side, which is conducive to the maximum utilization of the demand response potential of flexible loads and effectively reduce the power flow of heavy-load line.

The agglomeration effect caused by a large number of flexible load access will affect the existing dispatching operation mode of network in different degrees. At present, there are some research studies on flexible load participating in dispatching operation control of power grid at home and abroad which mainly focusing on the active response characteristics of flexible loads, load characteristics of electric vehicles, demand response scheduling strategies participating in wind power consumption and the influence on rotating reserve capacity, etc. However, there is little research on the model and algorithm of regional power grid optimization reconfiguration with flexible load. Therefore, it is urgent to carry out research on the key technologies of flexible load participating grid dispatching operation to support the integration of demand response dispatching and current dispatching methods.

Based on the load response characteristics of commercial buildings and residential users, this paper analyzes the potential of flexible load regulation. On this basis, the flexible load optimal combination control model based on the maximum comprehensive benefit is established, and the medium- and long-term control, day-ahead control, and real-time control methods of flexible load are studied. And the feasibility of flexible load resources directly participating in the load control system was analyzed. Based on the uncertainty and mathematical characterization method of 
the active response of flexible loads, the optimal combination control strategy of demand response resources was proposed to eliminate the problems of heavy load and overload of regional power grid equipment by using the active response ability of flexible loads. In this paper, the complementary potential of the hybrid energy system and the response priority mechanism of the integrated energy system equipment are analyzed from the aspects of technical and economic factors. The design model of the integrated energy coordinated control is optimized. Finally, the IEEE 14-node system is selected for simulation verification. It provides a theoretical basis for improving the dynamic balance ability of the power grid, alleviating the operating pressure of the power grid and improving the economic operating level of the power grid.

\section{An Analysis of Load Response Characteristics of Commercial Buildings and Residential Users Oriented to Courts}

2.1. An Analysis of Load Response Characteristics of Commercial Building. In the central air conditioning system, the operating power of the refrigerator takes the largest proportion of the operating power of the central air conditioning system. Therefore, only the refrigerators in the central air conditioning system are regulated and mathematically modeled.

Objective function:

$$
\max \left(P_{\text {pot }}\right)=\max \left(P_{\text {air }} \cdot \text { num_pot }\right)\left(t=T_{e_{-} \text {start }}, \ldots, T_{e_{-} \text {end }}\right) .
$$

In the above formula, $T_{e_{-} \text {start }}$ and $T_{e_{-} \text {end }}$ represent the start and end moments of emergency demand response events, respectively. During the duration of emergency demand response events, the load reduction of central air conditioning load group may be different at each moment, and the minimum load reduction over this period is defined as the regulation potential $P_{\text {pot }} . P_{\text {air }}$ is the operating power of a single central air conditioning refrigerator; num_pot is a decision variable to be optimized, and its significance is the number of central air conditioning refrigerators actually reduced corresponding to the regulation potential. Therefore, the significance of the objective function is to maximize the regulation potential of the central air conditioning load group during the emergency demand response event.

The constraints are as follows:

(1) Load reduction constraints during emergency demand response events

$$
P_{\text {base }}(t)-\sum_{k=1}^{n} P_{\text {air }} \cdot S(k, t) \geq P_{\text {pot }}\left(t=T_{e_{-} \text {start }}, \ldots, T_{e_{-} \text {end }}\right) .
$$

In equation (2), $P_{\text {base }}(t)$ represents the original overall operating power of the central air conditioning group at time $t$, that is, the load baseline of the central air conditioning load group; $\sum_{k=1}^{n} P_{\text {air }}$. $S(k, t)$ represents the overall actual operating power after the central air conditioning load group is controlled at time $t$, and $n$ represents the number of controlled central air conditioning in the central air conditioning load group; $S(k, t)$ represents the operating state of the refrigerator of the $k$-th central air conditioning at time $t, S(k, t)=1$ means that the refrigerator of the $k$-th central air conditioning is in operation at time $t$, and $S(k, t)=0$ means that the refrigerator of the $k$-th central air conditioning is in shutdown state at time $t$.

(2) Room temperature time-varying equation

According to the energy conservation principle, during the refrigeration period of the central air conditioning system, the indoor energy conservation equation can be obtained:

$$
\begin{aligned}
\rho_{a} \cdot V_{k} \cdot c_{a} \cdot \mathrm{d} T_{\text {in }}^{\text {on }}(t)= & Q_{t 1} \cdot \mathrm{d} t+Q_{\text {er }} \cdot \mathrm{d} t+Q_{\text {new }} \cdot \mathrm{d} t \\
& -Q_{t 2}-Q_{z}^{\text {on }} \cdot \mathrm{d} t,
\end{aligned}
$$

where $\rho_{a}$ is air density; $V_{k}$ is indoor volume; $c_{a}$ is the air's specific heat capacity; $T_{\text {in }}^{\text {on }}(t)$ is the indoor temperature within the period of $t$ in the refrigeration period; and $\rho_{a} \cdot V_{k} \cdot c_{a} \cdot \mathrm{d} T_{\text {in }}^{\text {on }}(t) \rho$ represents the heat obtained in the room during the $\mathrm{d} t$ period. By solving the first-order differential equation, the time-varying equation of indoor temperature in the refrigeration period can be obtained, shown as follows:

$T_{\text {in }}^{\text {on }}(t)=\frac{\alpha_{3}-Q_{p}}{\alpha_{2}}-\left[\frac{\alpha_{3}-Q_{p}}{\alpha_{2}}-T_{\text {in }}^{\text {on }}(0)\right] \cdot e^{-\left(\alpha_{2} / \alpha_{1}\right) \cdot t}$.

When the central air conditioning system is in shutdown period, its indoor energy conservation equation is

$$
\begin{aligned}
\rho_{a} \cdot V_{k} \cdot c_{a} \cdot \mathrm{d} T_{\text {in }}^{\text {off }}(t)= & Q_{t 1} \cdot \mathrm{d} t+Q_{\text {er }} \cdot \mathrm{d} t+Q_{\text {new }} \cdot \mathrm{d} t \\
& -Q_{t 2}-Q_{z}^{\text {off }} \cdot \mathrm{d} t .
\end{aligned}
$$

By solving the above first-order differential equation, the indoor temperature change equation during the shutdown period can be obtained, as follows:

$$
\begin{aligned}
T_{\text {in }}^{\text {off }}(t)= & \frac{\alpha_{3}}{\alpha_{2}}+\frac{\alpha_{4}}{a \cdot \alpha_{1}-\alpha_{2}} \cdot e^{-a \cdot t} \\
& -\left[\frac{\alpha_{4}}{a \cdot \alpha_{1}-\alpha_{2}}+\frac{\alpha_{3}}{\alpha_{2}}-T_{\text {in }}^{\text {off }}(0)\right] \cdot e^{-\left(\alpha_{2} / \alpha_{1}\right) \cdot t} .
\end{aligned}
$$

Specific expressions of some variables in the above equation are as follows: 


$$
\left\{\begin{array}{l}
\alpha_{1}=\rho_{a} \cdot V_{k} \cdot c_{a}+k_{s} \cdot S_{\text {wall }}^{\text {in }}, \\
\alpha_{2}=1.8 \cdot\left(k_{\text {top }} \cdot S_{\text {top }}+k_{\text {wall }} \cdot S_{\text {wall }}\right) \\
\alpha_{3}=\alpha_{2} \cdot T_{\text {out }}+Q_{\mathrm{er}} \\
\alpha_{4}=a \cdot m_{z} \cdot c_{w} \cdot\left(T_{\mathrm{w}-\text { out }}-T_{\mathrm{w}-\text { in }}\right)
\end{array}\right.
$$

where $V_{k}$ is the indoor volume; $c_{a}$ is the specific heat capacity of air; $k_{s}$ is the heat storage coefficient of the inner wall; $S_{\text {wall }}^{\text {in }}$ is the area of the inner wall; $k_{\text {top }}$ and $k_{\text {wall }}$ are the coefficients of heat conduction of the roof and wall, respectively; $S_{\text {top }}$ and $S_{\text {wall }}$ are the area of the roof and wall; $m_{z}$ is the quality of frozen water; $c_{w}$ is the specific heat capacity of frozen water; $T_{\mathrm{w}-\text { in }}$ and $T_{\mathrm{w} \text {-out }}$ are, respectively, the inlet and outlet water temperature of frozen water; and $Q_{e r}$ is the total cooling load of indoor equipment, lighting, and personnel.

(3) Upper and lower limits on room temperature changes

$$
\left\{\begin{array}{l}
T_{\text {in }}(k, t)=T_{\text {in }}^{\text {on }}(k, t) \cdot S(k, t)+T_{\text {in }}^{\text {off }}(k, t) \cdot[1-S(k, t)], \quad\left(t=T_{p_{-} \text {cool }}, \ldots, T_{e_{-} \text {start }}, \ldots, T_{e_{-} \text {end }}\right), \\
T_{\text {min }}(t) \leq T_{\text {in }}(k, t) \leq T_{\text {max }}(t)
\end{array}\right.
$$

where $T_{\max }(t)$ and $T_{\min }(t)$ represent the upper and lower limits of the temperature range at each time after the load group of central air conditioning is regulated by load aggregators. $T_{p_{-} \text {cool }}$ represents the start time of the advance notice period. Therefore, if the load aggregators use precooling control strategy, the advance notice period is $t=T_{p_{-} \text {cool }}, \ldots,\left(T_{e_{\text {_start }}}-1\right)$; otherwise, no advance notice is required, and at this time, $T_{p_{-} \text {cool }}=T_{e_{-} \text {start }}$.

(4) Minimum operating time constraint of refrigerator

$$
\left\{\begin{array}{l}
\sum_{t=T_{p-\text { cool }}}^{T_{p-\text { cool }}+G_{k}-1}[1-S(k, t)]=0, \\
\sum_{t=m}^{m+U T_{k}-1} S(k, t) \geq U T_{k}[S(k, n)-S(k, n-1)] \quad\left(\forall m=T_{p_{-} \text {cool }}+G_{k}, \ldots, T_{e_{-} \text {end }}-U T_{k}+1\right), \\
\sum_{t=n}^{T_{e-\text { end }}}\{S(k, t)-[S(k, t)-S(k, t-1)]\} \geq 0 \quad\left(\forall n=T_{e_{-} \text {end }}-U T_{k}+2, \ldots, T_{e_{-} \text {end }}\right), \\
G_{k}=\min \left\{\left(T_{e_{-} \text {end }}-T_{p_{-} \text {cool }}+1\right),\left[U T_{k}-U_{k}^{0}\right] S(k, 0)\right\} .
\end{array}\right.
$$

In equation (9), $U T_{k}$ represents the minimum operating time of the $k$-th central air conditioning refrigerating machine; $U_{k}^{0}$ represents the initial operating time of the $k$-th central air conditioning refrigerating machine; $S(k, 0)$ represents the initial operating state of the $k$-th central air conditioning refrigerating machine; and $G_{k}$ refers to the required operating time at least of the refrigerating machine in order to keep continuous with the operating state before control during the initial period after the start of the control. The third expression in equation (9) is to ensure that the operation state of the central air conditioning unit remains continuous before the end of the controlled state.

(5) Minimum downtime constraint of the refrigerator

$$
\left\{\begin{array}{l}
\sum_{t=T_{p_{-} \text {cool }}}^{T_{p-\text { cool }}+L_{k}-1} S(k, t)=0, \\
\sum_{t=m}^{m+D T_{k}-1}[1-S(k, t)] \geq \mathrm{DT}_{k}[S(k, n-1)-S(k, n)] \quad\left(\forall m=T_{p_{-} \text {cool }}+L_{k}, \ldots, T_{e_{-} \text {end }}-\mathrm{DT}_{k}+1\right), \\
\sum_{t=n}^{T_{e-\text { end }}}\{1-S(k, t)-[S(k, t-1)-S(k, t)]\} \geq 0 \quad\left(\forall n=T_{e_{-} \text {end }}-D T_{k}+2, \ldots, T_{e_{-} \text {end }}\right), \\
L_{k}=\min \left\{\left(T_{e_{-} \text {end }}-T_{p_{-} \text {cool }}+1\right),\left[\mathrm{DT}_{k}-Q_{k}^{0}\right][1-S(k, 0)]\right\} .
\end{array}\right.
$$


In the above formula, $\mathrm{DT}_{k}$ represents the minimum downtime of the $k$-th central air conditioning refrigerator; $Q_{k}^{0}$ represents the initial shutdown time of the $k$-th central air conditioning refrigerating machine; $L_{k}$ refers to the required shutdown time at least of the refrigerating machine in order to keep continuous with the operating state before control during the initial period after the start of the control. The third expression in equation (10) is to ensure that the operation state of the central air conditioning units remains continuous before the end of the controlled state.

(6) Constraints on the value range of decision variables

$$
\left\{\begin{array}{l}
S(k, t) \in\{0,1\} \quad\left(t=T_{\text {pre-cooling }}, \ldots, T_{e_{-} \text {start }}, \ldots, T_{e_{-} \text {end }}\right) \\
0 \leq \text { num_pot } \leq \min \left(\frac{P_{\text {base }}(t)}{P_{\text {air }}}\right) \quad\left(t=T_{e_{-} \text {start }}, \ldots, T_{e_{-} \text {end }}\right) .
\end{array}\right.
$$

The goal of the above central air conditioning load group regulation potential optimization model is to find the maximum number (num_pot) of central air conditioning refrigerators to be cut corresponding to the regulation potential in the objective function (1) and the operating state $(S(k, t))$ of each central air conditioning refrigerator at every moment controlled by the load aggregator under the condition that the constraints are satisfied.

The refrigerator's start-stop state matrix $S(k, t)$ contains the advance notice period of all central air conditioning refrigerators when the precooling regulation strategy is adopted and the state information of the emergency demand response event duration period. According to the state matrix obtained by optimization, the load aggregator can realize the regulation potential by adjusting the operating state of each central air conditioning refrigerator in these two periods. In addition, the room temperature will drop to the lower limit of room temperature at the end of the advance notice period to realize prerefrigeration; during the duration of emergency demand response events, reduce the air conditioning load according to the regulation potential obtained by optimization.

After the emergency demand response event, the central air conditioning refrigerators will be artificially and orderly controlled to gradually enter the operation state, so that the room temperature will return to the original room temperature range. When the room temperature enters the original room temperature range, the artificial control of the running state of the refrigerator will be cancelled.

In the model established above, only the relevant constraints of the refrigerator are considered; that is, the refrigerator is mainly used to achieve load reduction, which is a reasonable control method based on the consideration of communication and control complexity. If greater reduction is required, the air supply unit can be considered for regulation. When optimizing the air supply unit, the model is as follows.

The objective function:

$$
\max \left(P_{\text {pot }}\right)=\max \left(\min \left(P_{\text {base }}(t)-\left(P_{\text {air }} \cdot \sum_{k=1}^{n} S_{\text {air }}(k, t)+P_{\text {fan }} \cdot \sum_{k=1}^{n} S_{\text {fan }}(k, t)\right)\right)\right) \quad\left(t=T_{e_{-} \text {start }}, \ldots, T_{e_{-} \text {end }}\right) .
$$

where $P_{\text {base }}(t)$ is the baseline load taking into account the power of the forced draught blower; $P_{\text {air }}$ and $P_{\text {fan }}$ are, respectively, the power of refrigerator and air supply system; $S_{\text {air }}(k, t)$ and $S_{\text {fan }}(k, t)$ are, respectively, the operating states of the refrigerating machine and air supply system in the $k$-th building at time $t$. Therefore, the operating power of commercial buildings' air conditioning load group in time period $t$ is jointly determined by the operating states of refrigerators and air supply systems in each building, as shown in the following formula:

$$
P_{\text {total }}=P_{\text {air }} \cdot \sum_{k=1}^{n} S_{\text {air }}(k, t)+P_{\text {fan }} \cdot \sum_{k=1}^{n} S_{\text {fan }}(k, t) .
$$

Taking into account the regulation potential $P_{\text {pot }}$ of air conditioning load group of commercial buildings controlled by the air supply system, the expression is as follows:

$$
P_{\text {pot }}=\min \left(P_{\text {base }}(t)-\left(P_{\text {air }} \cdot \sum_{k=1}^{n} S_{\text {air }}(k, t)+P_{\text {fan }} \cdot \sum_{k=1}^{n} S_{\text {fan }}(k, t)\right)\right) .
$$


It is the minimum value of load reduction of commercial building air conditioning load group during emergency demand response event.

The constraints are as follows:

(1) Room temperature time-varying equation Indoor energy conservation equation:

$\rho_{a} \cdot V_{k} \cdot c_{a} \cdot \mathrm{d} T_{\text {in }}^{\text {off }}(t)=Q_{t 1} \cdot \mathrm{d} t+Q_{\text {er }} \cdot \mathrm{d} t+Q_{\text {new }} \cdot d t-Q_{t 2}$.

By solving the first-order differential equation, the room temperature time-varying equation under this condition can be obtained:

$$
T_{\text {in }}^{\text {off } 2}(t)=\frac{\alpha_{3}}{\alpha_{2}}-\left[\frac{\alpha_{3}}{\alpha_{2}}-T_{\text {in }}^{\text {off }}(0)\right] \cdot e^{-\left(\alpha_{2} / \alpha_{1}\right) \cdot t} .
$$

(2) Coupling constraints of the operating state of refrigerating unit and air supply system

$$
S_{\text {air }}(k, t)-S_{\text {fan }}(k, t) \leq 0 .
$$

It can be seen from the above formula that when the refrigerator is in operation state $\left(S_{\text {air }}(k, t)=1\right)$, the air supply system must also be in operation state $\left(S_{\text {fan }}(k, t)=1\right)$; when the refrigerator is off $\left(S_{\text {air }}(k, t)=0\right)$, the air supply system can be in either running state $\left(S_{\text {fan }}(k, t)=1\right)$ or off state $\left(S_{\text {fan }}(k, t)=0\right)$.

(3) Constraint of running time of the air supply system

$$
\sum_{t=T_{\text {pre-cool }}}^{T_{\text {end }}}\left(S_{\text {fan }}(k, t)-S_{\text {air }}(k, t)\right) \leq T_{\text {fan_on }} \cdot \text { Times }_{\text {on-off }} .
$$

The operating time of the air supply system is related to the change of the residual cooling capacity of chilled water. For the convenience of modeling, the running time of the air supply system is simplified to a fixed time $T_{\text {fan_on }}$; that is, the running time of the air supply system shall not exceed $T_{\text {fan_on }}$ during the shutdown period of the central air conditioning refrigerator.

\subsection{Analysis of Load Response Characteristics of Residential} Users. The objective function is consistent with that of air conditioning load in the commercial buildings. By controlling the air conditioning load of residential users, the maximum load reduction goal is achieved under the condition of satisfying the corresponding constraints, so that the potential of the air conditioning cluster can be fully developed.

In addition to one of the above objective functions, due to the variety and quantity of residents' air conditioning loads, in order to reduce the impact on users, the corresponding number of air conditioning units should be reduced as little as possible under the constraints of the maximum load reduction. The specific objective function is shown as follows:

$$
\min \left(x_{\text {run }}\right)=\min \left(\sum_{k=1}^{n} S(k, t)\right) \quad\left(t=T_{e_{-} \text {statrt }}, \ldots, T_{e_{-} \text {end }}\right) .
$$

The meanings of the above parameter are consistent with those in the air conditioning load model of commercial buildings where $x_{\text {run }}$ is the newly set variable representing the number of running machines at each time, and the objective function is added to make it affect the air conditioning load as little as possible under the condition of the maximum load reduction.

For constraint, it also includes the above constraints, namely, load reduction constraints during emergency demand response events, room temperature time-varying equations, constraints on upper and lower limits of room temperature variation, constraints on minimum operating time of air conditioning, constraints on minimum downtime of air conditioning, constraints on the value range of decision variables, etc. Most of the constraints contain the same contents as the air conditioning cluster load in commercial buildings. The main difference is that the startstop state matrix $S(k, t)$ of the air conditioning load only contains the state information of all residents' air conditioners during the duration of emergency demand response events but does not include the state in the advance notice period when the prerefrigeration control strategy is used. This is mainly because prerefrigeration measures for residential air conditioning load do not have its practicality. Similarly, according to the state matrix obtained by optimization, the load aggregator regulates the operating state of each resident's air conditioner during this period, so as to realize the regulation potential and reduce the air conditioning load according to the regulation potential obtained by optimization during the duration of emergency demand response events.

\section{Establish an Optimal Control Model for the Flexible Load Participating in the Power Grid Dispatching}

3.1. Analysis Method of Flexible Load Regulation Potential. In this paper, Xinjiekou Zhuanjinying Line \# 1(hereinafter referred to as Jinying \# 1) is selected as a typical representative of the power characteristics of the courts to analyze the load characteristics.

Table 1 shows the linear regression model summary of the load under the meteorological factor Jinying \# 1 feeder in summer (June, July, and August), focusing on the value of the determination coefficient $R$ squared. This coefficient indicates the percentage of the variance explained by the independent variable in the total variance. The greater the value, the greater the role of this factor. In the following table, the determination coefficient $R$ reaches $71.7 \%$, indicating that the regression relationship can explain the $71.7 \%$ variation of the dependent variable and has a good fitting degree. 
TABLE 1: Summary table of the linear regression model of Jinying \# 1 line load in summer.

\begin{tabular}{lccc}
\hline Model & $R$ & Adjusted $R$ & Error in standard estimates \\
\hline 1 & 0.717 & 0.703 & 18.423 \\
\hline
\end{tabular}

An analysis of variance was conducted on the model. The result of the analysis of variance showed that the $F$ value was 54.974, and the $P$ value was less than 0.05 . Therefore, the model was statistically significant or valuable for predicting variables.

The Table 2 gives the estimated value and test results of the constant term and regression coefficient in the regression equation. It can be seen that the constant term $=-31.001$, and the four regression coefficients are 139.900, 30.094, 12.826 , and 7.430 , respectively. The regression equation can be written as follows:

load value $=-31.001+139.900 \times$ temperature factor $+30.094 \times$ humidity factor

$+12.826 \times$ precipitation factor $+7.430 \times$ wind speed factor.

Table 3 shows a summary of the linear regression model of winter meteorological factor Jinying \# 1 load. The $R$ value in the model abstract is 0.859 , indicating that the regression relationship can explain $85.9 \%$ variation of the dependent variable. In Table 4 , Sig value is 0 , less than 0.05 , indicating that most independent variables in the model are correlated with dependent variables, indicating that the model has statistical significance.

Table 5 gives the estimated value and test results of the constant term and regression coefficient in the regression equation. The regression equation can be written as follows:

load value $=103.295-32.514 \times$ temperature factor $-2.414 \times$ humidity factor

$-5.539 \times$ precipitation factor $-0.884 \times$ wind speed factor.

According to the above construction method of the multifactor load characteristic regression model, each feeder can be independently analyzed, and the corresponding regression model of each feeder can be obtained, so that the feeder load value can be accurately predicted according to meteorological factors. According to different models in spring and summer, the load baseline mean values of feeders in spring and summer can be obtained. According to the difference between the two, the theoretical maximum load reduction potential can be obtained. According to this value, different load reduction potential targets can be formulated. After a large number of simulation calculations, the load reduction potential of each feeder under different prerefrigeration duration, different control duration, and different room temperature can be obtained. Finally, the flexible load regulation potential table can be obtained, as shown in Table 6.

\subsection{Establish an Optimal Combination Control Model of} Flexible Load Based on the Maximum Comprehensive Benefit. When the grid dispatching needs to regulate an interactive resource to complete a certain interactive task, the grid needs to pay the corresponding cost to the user, that is, the interactive cost of flexible load dispatching on grid side, no matter whether the price type load or the incentive load responds. At this time, with the change of the relationship between electricity price and power, the income of power grid will also change.
When the interactive resources on the flexible load side respond according to the price signal or incentive measures sent by the power grid, the electricity expense of the flexible load side will be different while the relationship between the electricity price and power changes. The variation of electricity expense is the interactive benefit of the flexible load side load response. Accordingly, the inverse value of the interaction benefit of load response represents the interactive cost of load response on the flexible load side. At the same time, the mode of electricity consumption will also change accordingly, which will affect the satisfaction of the mode of electricity consumption.

$C_{\text {inter }}$, the comprehensive interaction cost of flexible load demand response, can be expressed as

$$
\left\{\begin{array}{l}
C_{\text {inter }}=\sum_{t \in n_{T}}\left(\sum_{i \in n_{p}} C_{i, t}^{p}+\sum_{j \in n_{I}} C_{j, t}^{I}+\sum_{m \in n_{G}} C_{m, t}^{g}\right), \\
C_{m, t}^{g}=a_{m}\left(P_{m, t}^{g}\right)^{2}+b_{m} P_{m, t}^{g}+\lambda_{m, t} c_{m},
\end{array}\right.
$$

where $C_{\text {inter }}$ is the comprehensive interaction cost of flexible load demand response; $C_{i, t}^{p}$ is the scheduling cost of powerprice type flexible load $i$ in time period $t ; C_{j, t}^{I}$ is the dispatching cost of incentive flexible load $j$ in time period $t ; n_{p}$ is the quantity of flexible load of electricity price type; $n_{I}$ is the quantity of excitation type flexible load; $n_{G}$ is the amount of generators in the system; $C_{m, t}^{g}$ is the generating cost of the generator $m$ in the system during the period of time $t ; P_{m, t}^{g}$ is the active power output of the generator $m$ during the period 
TABLE 2: Table of coefficient of the linear regression model of Jinying \# 1 line load in summer.

\begin{tabular}{llccrr}
\hline & \multirow{2}{*}{ Model } & \multicolumn{2}{c}{ Nonstandard coefficient } & Normalized coefficient & $T$ \\
Beta & Sig \\
\hline 1 & (Constant) & -31.001 & 12.083 & - & -2.566 \\
2 & Temperature factor & 139.900 & 9.809 & 0.397 & 0.012 \\
3 & Humidity factor & 30.094 & 3.719 & 0.705 & 0.000 \\
4 & Precipitation factor & 12.826 & 1.500 & 0.207 & 8.092 \\
5 & Wind speed factor & 7.430 & 2.295 & 0.000 \\
\hline
\end{tabular}

TABle 3: Summary of the linear regression model of Jinying \# 1 line load in winter.

\begin{tabular}{lccc}
\hline Model & $R$ & Adjusted $R$ & Error in standard estimates \\
\hline 1 & 0.859 & 0.817 & 11.033 \\
\hline
\end{tabular}

TABLE 4: Variance diagram of the line load linear regression model of Jinying \# 1 in winter.

\begin{tabular}{lccccc}
\hline Model & Quadratic sum & Df & Mean square & $F$ & Sig (b) \\
\hline Regression & 6484.935 & 4 & 1621.234 & 13.319 & 0.000 \\
Residual & 5112.456 & 42 & 121.725 & & \\
\hline Total & 11597.391 & 46 & & & \\
\hline
\end{tabular}

of time $t ; a_{m}, b_{m}$, and $c_{m}$ are the power generation cost model coefficient of generator $m$; and $\lambda_{m, t}$ is a variable of $0-1$, which is 1 when the generator is put into operation in time period $t$, and 0 otherwise.

In this paper, the optimal dispatching is carried out aiming at maximizing the comprehensive benefits of "source-networkload." Since the numerical value of the comprehensive satisfaction degree of electricity consumption $(R)$ and the comprehensive interaction cost $\left(C_{\text {inter }}\right)$ do not belong to the same order of magnitude, it is necessary to normalize the $C_{\text {inter }}$ in order to ensure the optimization effect.

The objective function is as follows:

$$
\operatorname{Max} F=\operatorname{Max}\left(\frac{1}{n_{p}} \sum_{i \in n_{p}} R_{i}-\frac{C_{\text {inter }}}{\sum_{t \in n_{T}} \sum_{k \in n_{f}}\left(P_{k, t}^{0} \times p_{0}\right)}\right),
$$

where $R_{i}$ is the comprehensive electricity consumption satisfaction of power-price type load $i ; n_{f}$ is the total number of flexible loads; $p_{0}$ is the original unified power price of the system; and $P_{k, t}^{0}$ is the original load of the flexible load $k$ during the period of time $t$. There are mainly three constraints, which are unit constraint, system constraint, and load constraint, and the details are as follows:

(1) Unit constraints

The upper and lower limits of unit output:

$$
P_{g, m}^{\min } \leq P_{m, t}^{g} \leq P_{g, m}^{\max }, \quad m \in n_{G}
$$

where $P_{g, m}^{\min }$ and $P_{g, m}^{\max }$ indicate the lower and upper limits of the output of generator mseparately.

Unit climbing constraint:

$$
\left\{\begin{array}{l}
\lambda_{m, t} P_{m, t}^{g}-\lambda_{m, t-1} P_{m, t-1}^{g} \leq U_{g, m} \\
\lambda_{m, t-1} P_{m, t-1}^{g}-\lambda_{m, t} P_{m, t}^{g} \leq D_{g, m}
\end{array}\right.
$$

where $U_{g, m}$ and $D_{g, m}$, respectively, represent the upward and downward climbing constraint values of generator $m$.

Minimum start-stop time constraint of unit:

$$
\left\{\begin{array}{l}
\left(\lambda_{m, t}-\lambda_{m, t-1}\right) \cdot\left(T_{t-1}-T_{\text {on_ } m}\right) \geq 0 \\
\left(\lambda_{m, t}-\lambda_{m, t-1}\right) \cdot\left(T_{t-1}-T_{\text {off } \_m}\right) \leq 0
\end{array}\right.
$$

where $T_{t-1}$ is the duration of period $t-1$ and $T_{\text {on } \_m}$ and $T_{\text {off } \_} m$ are the minimum start-stop time of generator $m$, respectively.

(2) System constraints

Active power balance constraint:

$$
\sum_{k \in n_{f}} P_{k, t}=\sum_{m \in n_{G}} P_{m, t}^{g}
$$

where $P_{k, t}$ is the load of the flexible load $k$ during the period of time $t$ after participating in the demand response.

Network constraints:

$$
\begin{aligned}
\left|-b_{x y} \times\left(\theta_{x, t}-\theta_{y, t}\right)\right| \leq L_{x y}, \quad \forall t \in n_{T}, & \\
\forall x, y & \in\{1,2, \ldots, N\}, \quad \coprod x \neq y,
\end{aligned}
$$

where $b_{x y}$ is the electrical susceptance of line $x-y$; $\theta_{x, t}$ and $\theta_{y, t}$ separately represent the phase angles of nodes $x$ and $y ; L_{x y}$ is the maximum active power transmission capacity for line $x-y$; and $N$ is the amount of nodes in the system.

(3) Load constraint

There are mainly two load constraints which are load maximum adjustment constraints and excitation response invocation time constraints, and the details are as follows:

$$
\begin{aligned}
P_{k}^{\min } & \leq P_{k, t} \leq P_{k}^{\max }, \quad k \in n_{f}, \\
0 & \leq \operatorname{num}_{j} \leq n_{I_{-} j}^{\max }, \quad j \in n_{I},
\end{aligned}
$$

where $P_{k}^{\min }$ and $P_{k}^{\max }$ are the minimum and maximum of the incentive flexible load $j$, respectively; num ${ }_{j}$ is the number of times that the incentive flexible load $j$ is actually called; and $n_{I_{-} j}^{\max }$ is the maximum number of times that the incentive flexible load $j$ is called. 
TABle 5: Table of coefficient of the linear regression model of Jinying \# 1 line load in winter.

\begin{tabular}{llccrr}
\hline & \multirow{2}{*}{ Model } & \multicolumn{2}{c}{ Nonstandard coefficient } & Normalized coefficient & $T$ \\
& $B$ & Standard error & Beta & Sig \\
\hline 1 & (Constant) & 103.295 & 2.247 & -0.698 & 45.978 \\
2 & Temperature factor & -32.514 & 5.042 & -0.170 & -6.448 \\
3 & Humidity factor & -2.414 & 1.520 & -0.191 & -1.588 \\
4 & Precipitation factor & -5.539 & 3.026 & -1.830 \\
5 & Wind speed factor & -0.884 & 2.205 & -0.042 & 0.120 \\
\hline
\end{tabular}

TABLE 6: Flexible load regulation potential table.

\begin{tabular}{|c|c|c|c|c|}
\hline \multicolumn{5}{|c|}{ Outdoor temperature $31-33^{\circ} \mathrm{C}$} \\
\hline $\begin{array}{l}\text { Precooling duration } \\
(\mathrm{min})\end{array}$ & $\begin{array}{l}\text { Duration of event } \\
(\mathrm{min})\end{array}$ & $\begin{array}{l}\text { Upper limit of room temperature } \\
\qquad\left({ }^{\circ} \mathrm{C}\right)\end{array}$ & $\begin{array}{l}\text { Load reduction potential } \\
(\mathrm{MW})\end{array}$ & $\begin{array}{c}\text { Compensation fees } \\
\text { (yuan) }\end{array}$ \\
\hline \multirow{8}{*}{0} & \multirow{4}{*}{30} & 26 & 55 & 25740 \\
\hline & & 27 & 99 & 54054 \\
\hline & & 28 & 115.5 & 72072 \\
\hline & & 29 & 115.5 & 81081 \\
\hline & \multirow{4}{*}{40} & 26 & 44 & 29568 \\
\hline & & 27 & 77 & 60368 \\
\hline & & 28 & 115.5 & 103488 \\
\hline & & 29 & 115.5 & 116424 \\
\hline \multirow{8}{*}{10} & \multirow{4}{*}{30} & 26 & 115.5 & 59459.4 \\
\hline & & 27 & 115.5 & 69369.3 \\
\hline & & 28 & 115.5 & 79279.2 \\
\hline & & 29 & 115.5 & 89189.1 \\
\hline & \multirow{4}{*}{40} & 26 & 60.5 & 44721.6 \\
\hline & & 27 & 99 & 85377.6 \\
\hline & & 28 & 115.5 & 113836.8 \\
\hline & & 29 & 115.5 & 128066.4 \\
\hline
\end{tabular}

The dispatcher can get the optimal nodal power price, load reduction period and load reduction amount of each incentive flexible load, and the output arrangement of each power generating unit in each period through optimization, so as to issue scheduling instructions.

\section{A Comprehensive Optimization Control Strategy of Flexible Load for Courts}

Through the above analysis, the comprehensive optimization control strategy of flexible load under different time scales can be obtained to eliminate the line overload problem.

4.1. Medium- and Long-Term Regulation of Flexible Loads. For medium- and long-term load dispatching planning, the main consideration is the demand response model of load under the electricity price incentive of time-of-use electricity price and interruptible load. Its model is mainly manifested as response modeling of cumulative electric quantity at various periods of peak and valley level:

$$
\begin{aligned}
& \left\{\begin{array}{l}
q_{\mathrm{Ap}}=\sum_{i=1}^{n} q_{\mathrm{Aip}}, q_{\mathrm{Am}}=\sum_{i=1}^{n} q_{\mathrm{Aim}}, q_{\mathrm{Av}}=\sum_{i=1}^{n} q_{\mathrm{Aiv}}, \\
q_{\mathrm{Aip}}=q_{\mathrm{Aip} 0}+\frac{\varepsilon_{\mathrm{ppi}} q_{\mathrm{Aip} 0}\left(p_{\mathrm{TOUip}}-p_{\mathrm{TOUip} 0}\right)}{p_{\mathrm{TOUip} 0}}+\frac{\varepsilon_{\mathrm{pvi}} q_{\mathrm{Aip} 0}\left(p_{\mathrm{TOUiv}}-p_{\mathrm{TOUiv} 0}\right)}{p_{\mathrm{TOUiv} 0}}-\theta_{i} \Delta L_{\mathrm{IL} i}\left(t_{2 i}-t_{1 i}\right), \\
q_{\mathrm{Aim}}=q_{\mathrm{Aim} 0}, \\
q_{\mathrm{Aiv}}=q_{\mathrm{Aiv} 0}+\frac{\varepsilon_{\mathrm{vvi}} q_{\mathrm{Aiv} 0}\left(p_{\mathrm{TOUiv}}-p_{\mathrm{TOUiv} 0}\right)}{p_{\mathrm{TOUiv} 0}}+\frac{\varepsilon_{\mathrm{vpi}} q_{\mathrm{Aiv} 0}\left(p_{\mathrm{TOUip}}-p_{\mathrm{TOUip} 0}\right)}{p_{\mathrm{TOUip} 0}}
\end{array}\right.
\end{aligned}
$$


TABLE 7: Load expectation and variance at different time scales.

\begin{tabular}{|c|c|c|c|}
\hline Time scale & Electricity price incentives & Expectation & Variance \\
\hline Medium and long term & Time-of-use electricity price + interruptible load & $\left\{\begin{array}{l}q_{\mathrm{Ap}} \\
q_{\mathrm{Am}} \\
q_{\mathrm{Av}}\end{array}\right.$ & $\left\{\begin{array}{l}\sigma_{\mathrm{Ap}}^{2}=\sigma_{\mathrm{AMC}}^{2} \\
\sigma_{\mathrm{Am}}^{2}=0.264 \ln \left(\Delta q_{\mathrm{Am}}+1\right) \\
\sigma_{\mathrm{Av}}^{2}=0.264 \ln \left(\Delta q_{\mathrm{Av}}+1\right)\end{array}\right.$ \\
\hline Day-ahead & Day-ahead real-time electricity price + interruptible load & $P_{\mathrm{Ct}}$ & $\sigma_{C}^{2}= \begin{cases}\sigma_{\mathrm{CMCt}}^{2} & t_{1} \leq t \leq t_{2} \\
0.264 \ln \left(\Delta L_{\mathrm{Ct}}+1\right) & \text { else }\end{cases}$ \\
\hline Real-time & Real-time electricity & $P_{\mathrm{Dt}}$ & $\sigma_{D}^{2}=0.264 \ln \left(\Delta L_{\mathrm{Dt}}+1\right)$ \\
\hline
\end{tabular}

Note: $\sigma_{\mathrm{AMCt}}^{2}, \sigma_{\mathrm{BMCt}}^{2}$, and $\sigma_{\mathrm{CMCt}}^{2}$ represent the load variance values obtained by Monte Carlo simulation.

where $n$ represents the number of loads under a certain node; $\theta_{i}$ is the probability of the $i$-th load signing an interruptible contract; $\Delta L_{\mathrm{IL} i}$ is the amount of interruptible load of load $i$; and $t_{1 i} \sim t_{2 i}$ represents the start-stop time of the interruptible load for load $i$.

4.2. Day-Ahead Regulation of Flexible Load. For day-ahead load dispatching planning, the main consideration is the demand response model under day-ahead real-time power price and interruptible load:

$$
\begin{aligned}
P_{\mathrm{Ct}} & =\sum_{i=1}^{n} P_{\mathrm{Cit}}, \\
P_{\mathrm{Cit}} & =P_{\mathrm{Cit}}\left(p_{\mathrm{SPit}}\right)-\Delta P_{\mathrm{IL} i} .
\end{aligned}
$$

4.3. Real-Time Regulation of Flexible Load. For real-time load dispatching planning, the demand response model of load under the incentive of real-time power price is considered. Its main features are shown as follows:

(1) Price elasticity of demand will be different while power price changes.

(2) The load at the next moment is the result of superposition of load response components based on the load at the previous moment.

$$
\begin{aligned}
P_{\mathrm{Dt}+1} & =\sum_{i=1}^{n} P_{\mathrm{Dit}+1}, \\
P_{\mathrm{Dit}+1} & =P_{\mathrm{Dit}}+\frac{\varepsilon_{i}\left(p_{\mathrm{SPit}+1}\right) P_{\mathrm{Dit}}\left(p_{\mathrm{SPit}+1}-p_{\mathrm{SPit}}\right)}{p_{\mathrm{SPit}}} \\
\varepsilon_{i}\left(p_{\mathrm{SPit}+1}\right) & =\frac{\partial P_{i}\left(p_{\mathrm{SPit}+1}\right)}{\partial p_{\mathrm{SPit}+1}} .
\end{aligned}
$$

According to the above analysis, the expectation and variance of load under different time scale responses can be obtained, as shown in Table 7.

\section{Example Analysis}

The IEEE 33-node system in the literature [26] was selected for example analysis. The IEEE 33-node system is shown in Figure 1. There are 5 generators in the system, which are located on nodes $8,12,17,19$, and 22 . Tables $8-10$ show the system's nodes, active power output, circuit, and load parameters. The unit of cost coefficient $a, b, c$ are $\$ / \mathrm{MW} 2$, $\$ / \mathrm{MW}$, and \$, respectively, and the units of impedance and ground capacitance are $\Omega$.

In Table 10, all users can participate in price-based demand response. Users 1 to 10 participate in incentive demand response, which is divided into translational, reducible, and transferable classes. Take $\mu_{1}=\mu_{2}=0.5$, take $K=1, \alpha=0.15$, and the original price $p_{0}=42.7$ in the electricity price response model. When the breaker breaking capacity constraint is not taken into account, the optimal power flow is adopted to calculate and obtain the active power output data of each generator in 24 periods, as shown in Table 11. The active power flow of each branch is shown in Table 12.

The maximum breaking capacity of circuit breakers on each line is $300 \mathrm{MW}$. It can be seen from Table 12 that the power flow of lines 7-8 and 7-9 exceeds the limit in some time periods. To eliminate the network congestion of lines 7-8 and 7-9, four different scenarios are constructed in the literature [26]. Scenario settings are shown in Table 13.

In the four scenarios, MATLAB was used for simulation calculation. The computer CPU was Intel(R) Core(TM) I54590 , the main frequency was $3.3 \mathrm{GHz}$, and the memory was $8 \mathrm{~GB}$. The optimized simulation time in each scenario is 10.57 s, 24.07 s, 28.1 s, and 57.03 s, respectively.

The optimized active power flow curves of lines 7-8 and 7-9 are shown in Figures 2 and 3.

In Scenario 1, the output of the generator is adjusted without considering the demand response. The optimized output of each generator node is shown in Table 14 .

As can be seen from Figures 2 and 3, in Scenario 1, the power flow of the blocked line can only be reduced to $340 \mathrm{MW}$ by adjusting the output distribution of the power generation side to the minimum, and the problem of power flow beyond the limit cannot be eliminated. At the same time, it can be seen from Table 14 that when the overload of line active power flow is eliminated, the variation of active power output of generator nodes 17 and 19 is too large, which is difficult to be realized in the actual power grid.

However, in Scenarios 2, 3, and 4, due to the implementation of integrated dispatching for power generation and consumption side at the same time, the off-limit power flow is under ideal control, and under this dispatching mode, the blocked line still has room for power flow to fall. 


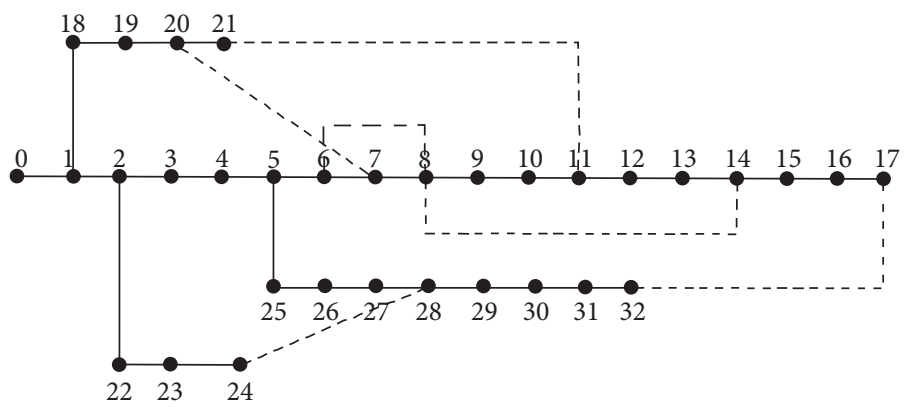

FIGURE 1: IEEE 33-node system.

TABle 8: Active power output data of the IEEE 33-node system.

\begin{tabular}{lccc}
\hline \multirow{2}{*}{ Node number } & Upper limit of active power output/(MW) & Lower limit of active power output/(MW) & \multicolumn{2}{c}{ Cost coefficient } \\
& & $b$ & $c$ \\
\hline 8 & 300 & 0 & 0 \\
12 & 300 & 0 & 300 \\
17 & 350 & 0 & 3 \\
19 & 350 & 0 & 300 \\
22 & 500 & 0 & 3 \\
\hline
\end{tabular}

5.1. Interactive Cost Analysis of Flexible Loads. The interaction costs of flexible loads in each scenario are shown in Table 15.

The comparison of unit power generation costs in each scenario is shown in Table 16:

Since the network congestion cannot be eliminated only through generation side dispatching in Scenario 1, the interaction cost in Scenario 1 is not analyzed.

As can be seen from Table 15, in Scenario 4, when electricity price and incentive comprehensive response scheduling are adopted, the total interactive cost is the minimum. This is mainly because the collaborative scheduling on the generating and consuming side can effectively reduce the output of high-cost units on the basis of ensuring the power consumption and increase the output of the lowcost units, so as to effectively reduce the total cost of power generation and effectively reduces the cost of electricity price response and incentive response of load under the comprehensive action of electricity price and incentive at the same time.

And in Scenario 3, although the interaction response cost on the load side (electricity price response cost + incentive response cost) is the lowest, it calls more high-cost units (the total output of units 8 and 12 is $4756 \mathrm{MW}$ in Scenario 3, only $3961 \mathrm{MW}$ in Scenario 4), making its unit power generation cost (from Table 16) higher, pushing up the total cost of the interaction. In addition, it can be found from the data that, under the same dispatching adjustment effect, the total interactive cost of electricity price response is obviously smaller than that of incentive response.

5.2. Comparison of Comprehensive Satisfaction with Electricity Consumption. Under different scenarios, the comprehensive satisfaction of electricity consumption is shown in Table 17:
TABle 9: Line parameters of the IEEE 33-node system.

\begin{tabular}{lcc}
\hline Branch circuit & Branch impedance & Ground capacitance \\
\hline $0-1$ & $0.0922+j 0.047$ & 0.0412 \\
$1-2$ & $0.01938+j 0.05917$ & 0.0528 \\
$2-3$ & $0.04699+j 0.19797$ & 0.0438 \\
$3-4$ & $0.05811+j 0.17632$ & 0.0374 \\
$4-5$ & $0.05403+j 0.22304$ & 0.0492 \\
$5-6$ & $0.05695+j 0.17388$ & 0.0340 \\
$6-7$ & $0.06701+j 0.17103$ & 0.0346 \\
$7-8$ & $0.00000+j 0.17615$ & 0.0000 \\
$7-9$ & $0.00000+j 0.11001$ & 0.0000 \\
$8-9$ & $1.0440+j 0.7400$ & 0.0000 \\
$9-10$ & $0.1966+j 00650$ & 0.0000 \\
$10-11$ & $0.3744+j 0.1238$ & 0.0000 \\
$11-12$ & $1.4680+j 1.550$ & 0.0000 \\
$12-13$ & $0.5416+j 0.7129$ & 0.0000 \\
$13-14$ & $0.5910+j 0.5620$ & 0.0000 \\
$14-15$ & $0.7463+j 0.5450$ & 0.0000 \\
$15-16$ & $1.2890+j 1.7210$ & 0.0000 \\
$1-18$ & $0.09498+j 0.1989$ & 0.0000 \\
$18-19$ & $0.12291+j 0.25581$ & 0.0000 \\
$19-20$ & $0.06615+j 0.13027$ & 0.0000 \\
$20-21$ & $0.12711+j 0.27038$ & 0.0000 \\
$2-22$ & $0.08205+j 0.19207$ & 0.0000 \\
$22-23$ & $0.22092+j 0.19988$ & 0.0000 \\
$23-24$ & $0.17093+j 0.34802$ & 0.0000 \\
$5-25$ & $0.2030+j 0.1034$ & 0.0000 \\
$25-26$ & $0.2842+j 0.1447$ & 0.0000 \\
$26-27$ & $1.0590+j 0.9337$ & 0.0000 \\
$27-28$ & $0.8042+j 0.7006$ & 0.0000 \\
$28-29$ & $0.5075+j 0.2585$ & 0.0000 \\
$29-30$ & $0.9744+0.9630$ & 0.0000 \\
$30-31$ & $0.3105+j 0.3619$ & 0.0000 \\
$31-32$ & $0.3410+j 0.5362$ & 0.0000 \\
\hline & & \\
\hline & &
\end{tabular}

As can be seen from the chart, since there is no electricity response in Scenarios 1 and 3, electricity comprehensive satisfaction is 1 , and the comprehensive satisfaction with 


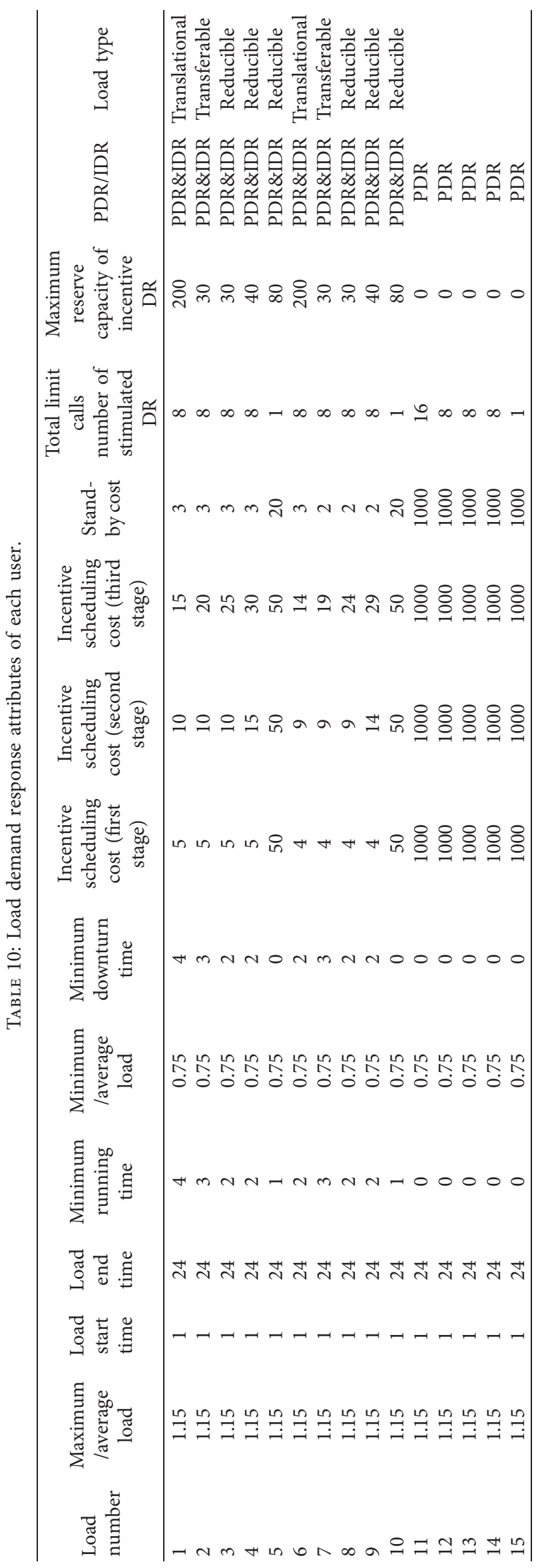




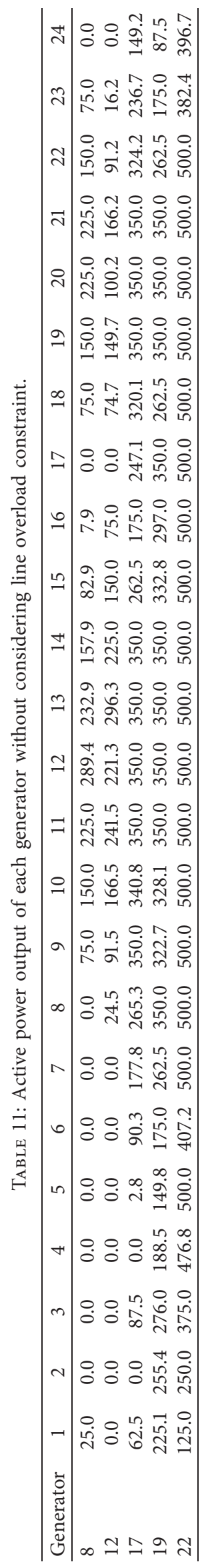




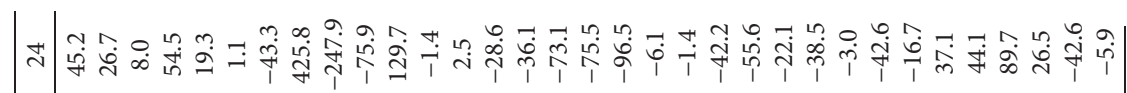

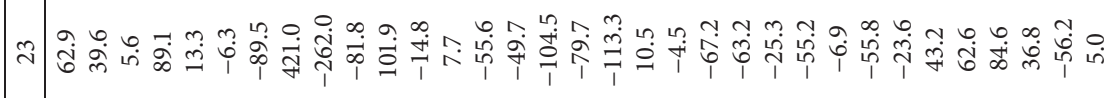

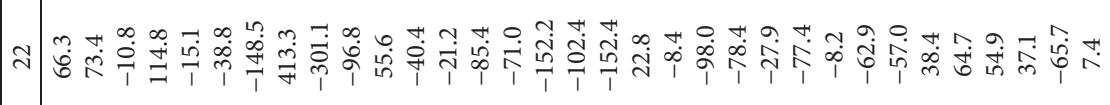

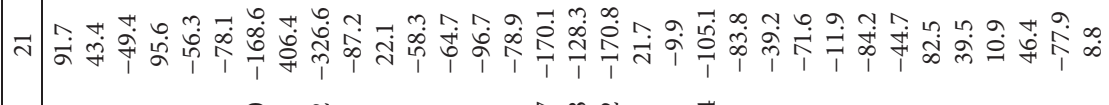

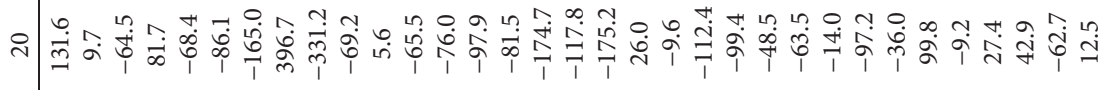

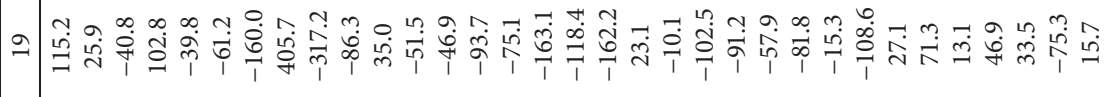



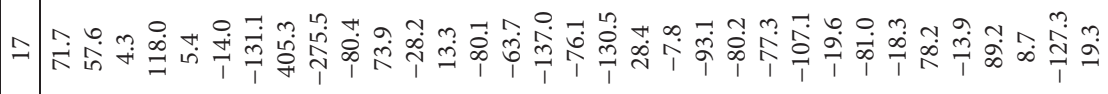

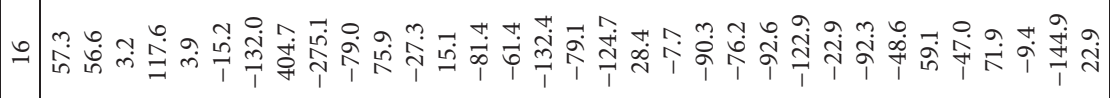

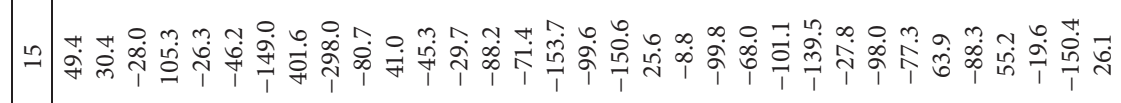

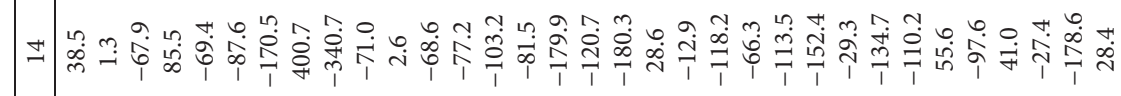

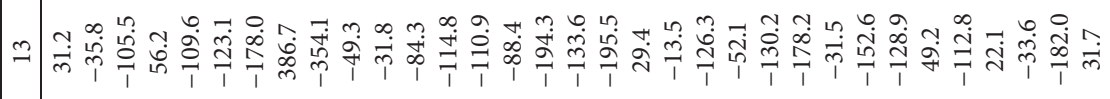

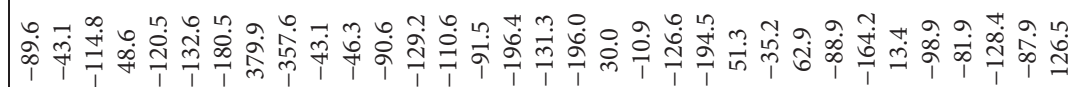

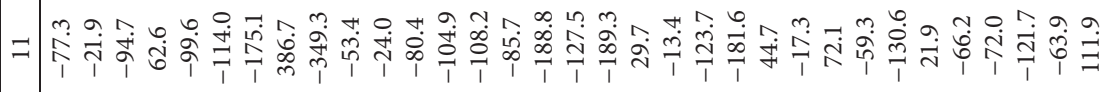

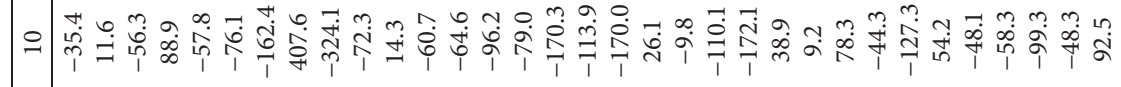

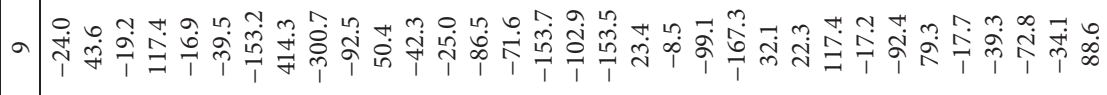

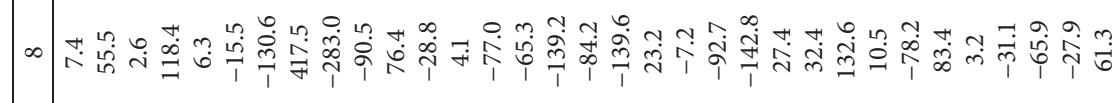

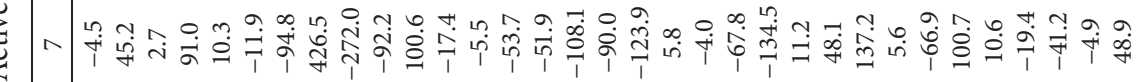

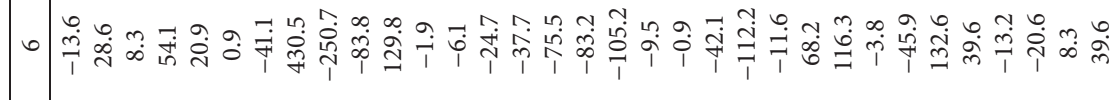

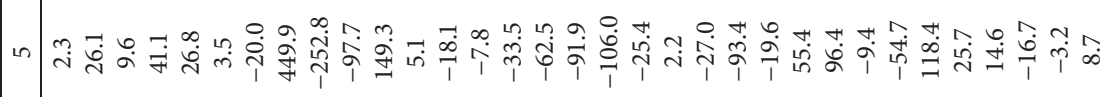

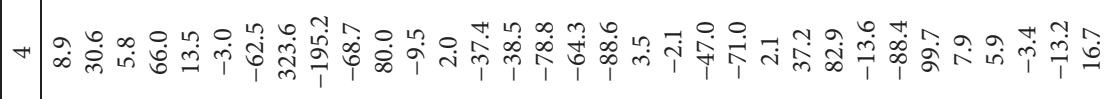

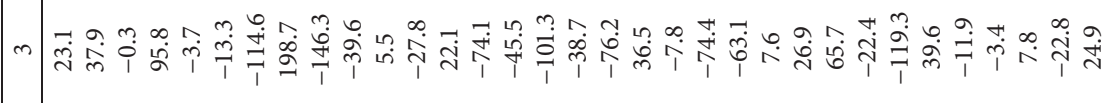

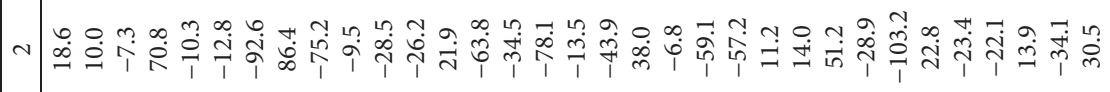

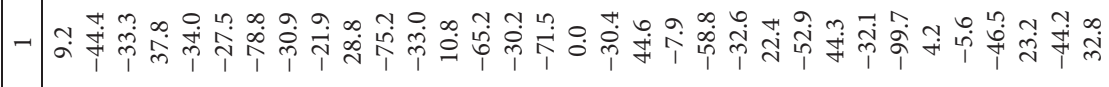

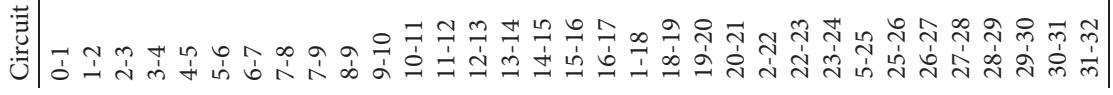


TABLE 13: Four different scenarios for eliminating network congestion.

Scene

sequence

Scenario 1

Scenario 2

Scenario 3

Scenario 4

\section{Scene settings}

Eliminating network congestion only by generation side dispatching

Adjust generation output and implement electricity price dispatch on load side to eliminate network congestion

Adjust generation output and implement incentive dispatch on load side to eliminate network congestion

Adjust generation output and implement electricity price and incentive dispatch on load side to eliminate network congestion (integrated dispatch of generation and consumption)

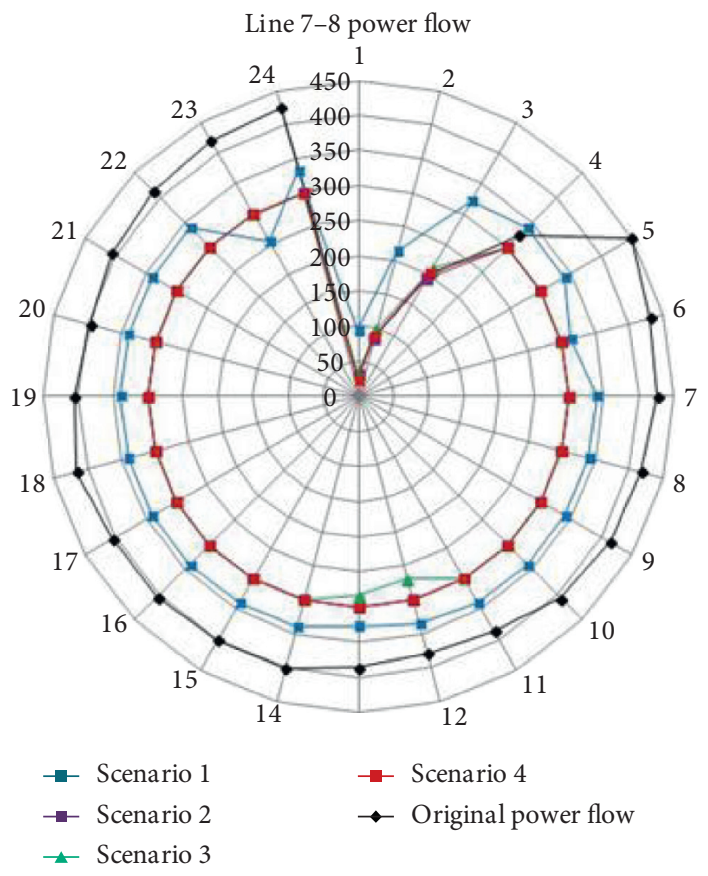

FIgURE 2: Active power flow curve of line 7-8 after optimized scheduling in different scenarios.

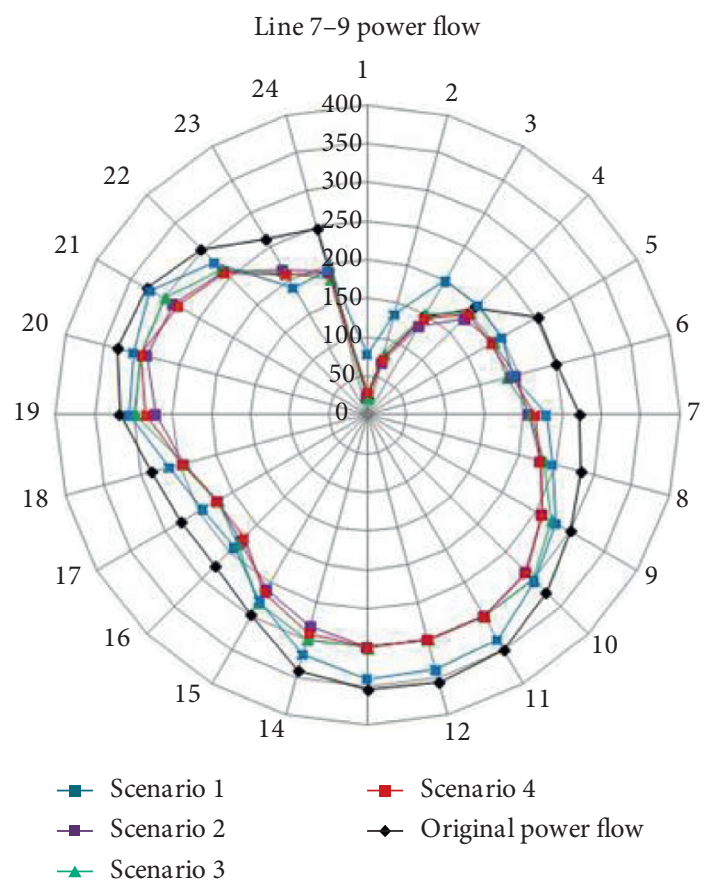

FIgURE 3: Active power flow curve of line 7-9 after optimized scheduling in different scenarios. 


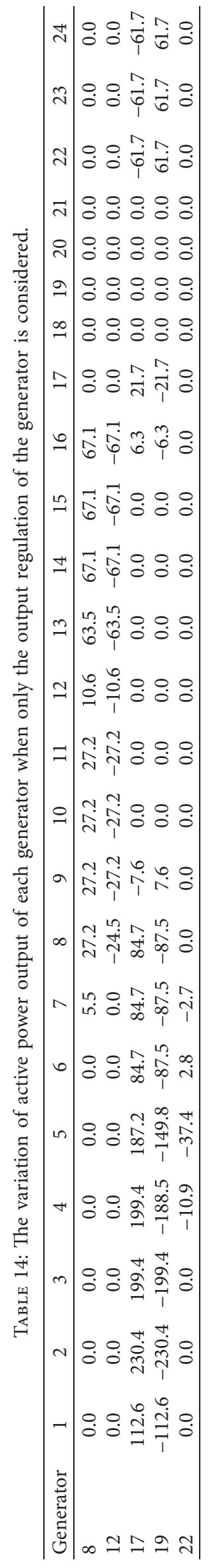


TABLE 15: Comparison of load interaction costs under different scenarios.

\begin{tabular}{lcccc}
\hline Scenario & Total cost of interaction & Total cost of generation & Electricity price response cost & Incentive response cost \\
\hline Scenario 1 & 733430 & 733430 & 0 & 0 \\
Scenario 2 & 749350 & 733359 & 15991 & 0 \\
Scenario 3 & 759660 & 751539 & 0 & 8121 \\
Scenario 4 & 743190 & 731929 & 9462 & 1799 \\
\hline
\end{tabular}

TABLE 16: Comparison of unit power generation cost after response scheduling in different scenarios.

\begin{tabular}{lccc}
\hline Scenario & Total cost of generation & Gross generation & Unit generation cost \\
\hline Scenario 1 & 733430 & 27440.43 & 26.73 \\
Scenario 2 & 733359 & 27419.21 & 26.75 \\
Scenario 3 & 751539 & 27506.64 & 27.32 \\
Scenario 4 & 731929 & 27593.08 & 26.53 \\
\hline
\end{tabular}

TABLE 17: Comparison of comprehensive satisfaction with electricity consumption after response scheduling in different scenarios.

\begin{tabular}{lccc}
\hline Scenario & Satisfaction of power consumption mode & Interactive benefit satisfaction & Comprehensive satisfaction \\
\hline Scenario 1 & 1 & 1 & 1 \\
Scenario 2 & 0.815 & 1.043 & 0.929 \\
Scenario 3 & 1 & 1 & 1 \\
Scenario 4 & 0.987 & 0.996 & 0.992 \\
\hline
\end{tabular}

electricity consumption in Scenario 4 is greater than that in Scenario 2. This is mainly due to the addition of incentive response mechanism in Scenario 4, and the incentive scheduling plan is formulated according to the load interruptible plan independently reported by users. In this case, the autonomous power consumption willingness of flexible load can be guaranteed to the maximum extent. Leading to a high degree of satisfaction with its power consumption mode. In Scenario 2, although the user obtains a certain income from electricity fee through the response of electricity price, the mode of electricity consumption changes greatly, which leads to a low degree of comprehensive satisfaction with electricity consumption.

It can be found from the comparison of comprehensive economic benefits and satisfaction that when network congestion occurs, in Scenario 4, the optimal scheduling mode of adjusting power generation output and simultaneously implementing electricity price and incentive scheduling on the load side to eliminate network congestion (integrated comprehensive scheduling of power generation and electricity consumption) is relatively the most appropriate.

\section{Conclusions}

In this paper, the mathematical model of air conditioning load in commercial buildings and residential users is established, and the response characteristics of commercial buildings and residential users are analyzed. On this basis, Xinjiekou Zhuanjinying Line \# is selected as the typical representative of the power consumption characteristics of the courts to analyze the load characteristics, and the flexible load regulation potential table is obtained. A flexible load optimal combination control model based on the maximum comprehensive benefit was established, and through this model, the dispatcher can obtain the optimal node electricity price, load reduction period and load reduction amount of each incentive flexible load, and the output arrangement of each generator set in each period, so as to issue scheduling instructions. Finally, the comprehensive optimization control strategy of the flexible load oriented to the courts is proposed, and the medium- and long term-regulation, day-ahead regulation, and real-time regulation methods of the flexible load are studied, and the IEEE 14-node system is selected for example analysis.

In this paper, the complementary potential of the hybrid energy system and the response priority mechanism of the integrated energy system equipment are analyzed from the aspects of technical and economic factors. The design model of the integrated energy coordinated control is optimized, and the solution analysis is carried out by using the multitime scale cooperative control strategy. Through the analysis of the example, the optimal scheduling results of multitime scale of source storage load are obtained. This study is of great significance for the construction of the hybrid energy system, the promotion of new energy consumption, the increase of energy storage application in power grid, and the realization of more sustainable energy management.

\section{Data Availability}

The data used to support findings of this study are available from the corresponding author upon reasonable request.

\section{Conflicts of Interest}

The authors declare that there are no conflicts of interest regarding the publication of this paper 


\section{Acknowledgments}

This study was supported by the Research and Application of Key Technologies for Accurate Control of Station Load and Smart Energy Consumption for Network-Load Cooperation (5400-202018421A-0-0-00).

\section{References}

[1] S. C. Lee and S. J. Kim, S. H. Kim, Demand side management with air conditioner loads based on the queuing system model," IEEE Transactions on Power Systems, vol. 26, no. 2, pp. 661-668, 2011.

[2] L. Zhou, L. Yang, and C. Gao, "Improvement of temperature regulation method and control strategy of convergent air conditioning load," in Proceedings of the 2014 International Conference on Circuits Systems and Electronics Engineering, Kuala Lumbur, Malaysia, March 2014.

[3] Y. Zhang, Study on Evaluation and Application of Load Participation System for Peak Load Regulation, Shandong University, Shadong, China, 2020.

[4] T. W. Haring, J. L. Mathieu, and G. Andersson, "Comparing centralized and decentralized contract design enabling direct load control for reserves," IEEE Transactions on Power Systems, vol. 31, no. 3, pp. 2044-2054, 2016.

[5] S. Xujun, J. Bei, L. Wenbo et al., "Investigation and analysis of air conditioning cooling load of residents in summer in Hefei," Power Demand Side Mangement, vol. 10, no. 4, pp. 27-29, 2008.

[6] Z. Lu, Analysis of Load Characteristics and Energy Consumption of Air Conditioning in High-Rise Office Buildings in Chongqing, Chongqing University, Chongqing, China, 2007.

[7] X. Mingwei, X. Ming, C. Chunhong et al., "Research and forecast modeling of air conditioning load characteristics in summer," Method, vol. 52, pp. 2007-2008, 2009.

[8] E. S. Parizy, H. R. Bahrami, and S. Choi, "A low complexity and secure demand response technique for peak load reduction," IEEE Transactions on Smart Grid, vol. 10, no. 3, pp. 3259-3268, 2019.

[9] T. Vincenzo, T. Fei, and S. Goran, "Role and benefits of flexible thermostatically controlled loads in future low-carbon systems," IEEE Transactions on Smart Grid, vol. 9, no. 5, pp. 5067-5079, 2018.

[10] A. Zhen, H. Yuqi, Y. Xi et al., "Research on load control technology of central air conditioning based on demand response," Power Communication Management \& Smart Grid Communication Technology Forum Proceedings, vol. 42,, 2012.

[11] M. Liu, X. Chu, W. Zhang et al., "A scheduling control strategy for air conditioning load group based on diversity preservation," in Proceedings of the International Conference on Circuits Systems and Electronics Engineering, 2014, Kuala Lumpur, Malaysia, March 2014.

[12] Q. Xu, C. Yang, and Q. Yan, "Day-ahead peak clipping strategy of power load considering thermal balance inertia of large-scale air conditioning," Power System Technology, vol. 40, no. 1, pp. 156-163, 2016.

[13] B. J. C. van Putten, N. Mahdavi, J. H. Braslavsky, and Braslavsky, "An analytical model for demand response of variable-speed air conditioners," IFAC-Papers OnLine, vol. 51, no. 28, pp. 426-431, 2018.

[14] X. Liu, B. Wang, L. Yang, and Y. Jianguo, "Generation dayahead scheduling model with user-side interaction in smart grid," Proceedings of International Conference on Circuits
Systems and Electronics Engineering, vol. 33, no. 1, pp. 30-38, 2013.

[15] L. Won-Woo, "US lessons for energy industry restructuring: based on natural gas and California electricity incidences," Energy Policy, vol. 32, pp. 237-259, 2011.

[16] M. Nariman, H. Braslavsky Julio, M. Seron Maria et al., "Model predictive control of distributed air-conditioning loads to compensate fluctuations in solar power," IEEE Transactions on Smart Grid, vol. 8, no. 6, pp. 3055-3065, 2017.

[17] L. Weijia, W. Qiuwei, W. Fushuan et al., "Market mechanisms for electric vehicles and controllable loads to participate in distribution system congestion management," Automation of Electric Systems, vol. 38, no. 24, pp. 26-33, 2014.

[18] X. Ma, W. Chao, H. Xiao, L. Ying, and W. Hao, "Optimization strategy of double-layer charging for electric vehicles based on node blocking price," Power System Technology, vol. 40, no. 12, pp. 3707-3714, 2016.

[19] S. Qian, P. Jianchun, P. Juntao et al., "Blocking management of multi-time power demand response," Power System Technology, vol. 34, no. 9, pp. 139-143, 2010.

[20] S. Zhang, W. Qin, Z. Yao et al., "Blocking management of power bilateral transactions based on interruptible load auction model," Power System Protection and Control, vol. 39, no. 22, pp. 122-128, 2011.

[21] Q. Shi and L. Shidong, "Interruptible loads participate in blocking management model and characteristics analysis," Proceedings of the CSUEPSA, vol. 27, no. 7, pp. 48-53, 2015.

[22] P. Yan, Z. Binqiao, and X. Deng, "Study on transmission congestion management model in power market," Telecom Power Technologies, vol. 33, no. 4, pp. 36-38, 2016.

[23] L. Caihua, D. Songhuai, C. Zhiwen et al., "Optimal scheduling of interruptible load for blocking management under LMP mechanism," Power System Protection and Control, vol. 36, no. 4, pp. 67-71, 2008.

[24] X. Kong, Y. Qun, M. Yunfei et al., "Analysis method of user load demand response under time-of-use electricity price," Proceedings of the CSUEPSA, vol. 27, no. 10, pp. 75-80, 2015.

[25] X. Jia, H. Zhong, Q. Xia et al., "Transmission congestion management method based on incentive coupon mechanism," Power System Technology, vol. 37, no. 5, pp. 1291-1298, 2013.

[26] X. Shao, Y. Zhou, and G. Cui, "Research on optimal control method of customer-side controllable load energy consumption," in Proceedings of the 2020 Chinese Automation Congress, CAC 2020, pp. 4365-4370, Shanghai, China, November 2020. 